\title{
UMA PROPOSTA DE CLASSIFICAÇÃO DAS COMPETÊNCIAS/HABILIDADES DAS DIRETRIZES CURRICULARES NACIONAIS EM SOFT E HARD SKILLS
}

DOI: 10.37702/2175-957X.COBENGE.2021.3586

Richardson Bruno Carlos Araújo - acbr2015@gmail.com

UFERSA

Rua Princesa Isabel 330

59012-400 - Natal - RN

Luciana Torres Correia de Mello - lucianatcmello@yahoo.com.br

UFERSA

Rua Lucia Viveiros 649

59086-005 - Natal - RN

Resumo: $O$ processo formativo do ensino em engenharia precisou ser reestruturado a fim de que os profissionais atuem conforme as necessidades do mercado de trabalho e da sociedade. Assim, a Resolução CNE/CES no2, de 24 de abril de 2019, institui Diretrizes Curriculares Nacionais (DCNs) do Curso de Graduação em Engenharia, as quais promovem mudanças, ao comparar-se com as anteriores. Dentre estas, a concepção do currículo por competências é um dos pontos mais inovadores. Assim, este trabalho propõe uma classificação das competências listadas nas DCNs em hard e soft skills. Pois com a necessidade imposta no ambiente universitário, na qual a transmissão de conhecimentos técnicos é suplantada pelo desenvolvimento de competências, habilidades e atitudes que formem cidadão-engenheiros, é relevante a classificação consoante aos registros da literatura que elucidam a necessidade de o indivíduo possuir soft skills e hard skills para conseguir um lugar de destaque no mercado. Para isso, são utilizadas a pesquisa documental, seguida da pesquisa bibliográfica. Os resultados obtidos, com uso da técnica de análise cruzada das informações resulta que das 24 competências gerais esperadas do egresso em Engenharia: nove são categorizadas como hard skills e as outras 15 competências classificam-se em soft skills, mediante a literatura consultada. Assim, são hard skills aplicação de conceitos de gestão, verificação e validação de modelos por meio de técnicas adequadas. E são classificadas como soft skills habilidades como o desenvolver sensibilidade global nas organizações e realizar avaliação crítico- reflexiva dos 


\section{COBENCE - Evento onine

impactos das soluções em engenharia nos contextos social, legal, econômico e ambiental.

Palavras-chave: Competências. Habilidades. Perfil do egresso. Hard skills. Soft skills. 


\section{UMA PROPOSTA DE CLASSIFICAÇÃO DAS COMPETÊNCIAS/HABILIDADES DAS DIRETRIŽES CURRICULARES NACIONAIS EM SOFT E HARD SKILLS}

\section{INTRODUÇÃO}

As características do estudante contemporâneo têm sido pauta das discussões em diversas situações de ensino. Estas, motivadas pelos índices elevados de insucesso, abandono, além da falta de motivação e comprometimento com a aprendizagem (ELMÔR FILHO et al., 2019). No contexto da Engenharia, no Brasil, os desafios ainda são maiores em vista do processo de implantação da Educação Superior e outras variáveis históricas e sociais do país.

Conforme elucidam Bazzo e Costa (2019), para a formação de profissionais da área tecnológica, a associação dos desenvolvimentos humano e tecnológico é imperativa frente aos recentes atentados e desastres ambientais. Além disso, existe a dificuldade de seleção de engenheiros qualificados que consigam atuar como requerido pelo mercado: alinhando as dimensões técnicas, cognitivas e comportamentais adequadas à cultura da economia criativa e digital (PRADO, DONATO; 2019).

Como resposta à necessidade do perfil profissional exigido pelo mercado e a fim de promover a modernização dos cursos de Engenharia ao novo contexto social, o Conselho Nacional de Educação (CNE) instituiu, em 2019, as Diretrizes Curriculares Nacionais (DCN) dos cursos de Engenharia. As DCNs instituem a gestão da aprendizagem nas Instituições de Ensino Superior (IES) baseada no desenvolvimento de competências, habilidades e atitudes, considerando metodologias ativas, o processo cognitivo dos estudantes e exposição de problemas realistas (BRASIL, 2019). Espera-se, como produto, estudantes com maior autonomia, aprendizado, sensação de pertencimento ao processo e protagonismo profissional (PRADO, DONATO; 2019).

Assim, dentre os desafios na implementação das DCNs, a organização do Projeto Pedagógico do Curso possui aspectos desafiadores como a revisão curricular, a atuação docente, autonomia das IES em face da flexibilidade das DCNs e a gestão da aprendizagem. Para este último aspecto, Angelo e Gianesi (2019) consideram que as competências do egresso são norteadoras do processo ensino-aprendizagem e devem ser desdobradas em indicadores claros e mensuráveis viabilizando a avaliação com uso de instrumentos específicos.

No contexto discutido, este artigo traz uma proposta de classificação das competências gerais trazidas nas DCNs dos cursos de Engenharia, em hard e soft skills. Portanto, é um estudo teórico que elenca as competências do instrumento legal, discute brevemente a teoria associada às competências e habilidades, finalizando com a proposta de categorização. A relevância do artigo é iniciar a discussão da gestão da aprendizagem das DCNs nas IES, uma vez que com a categorização pode-se construir instrumentos genéricos de avaliação das competências, seguidos de recursos específicos.

\section{AS COMPETÊNCIAS E HABILIDADES DAS ENGENHARIAS}

A transição do currículo mínimo para o currículo por diretrizes são momentos distintos que complementam o histórico de evolução da Educação no país. Enquanto o currículo mínimo objetivava uniformizar as condições e qualidade dos cursos de formação 
profissional, as diretrizes asseguram a flexibilidade e heterogeneidade necessárias para enfrentar os desafios das rápidas transformações do mercado de trabalho, e da sociedade do exercício profissional (BRASIL, 1997). Assim, no campo da engenharia, as DCNs objetivam definir princípios, fundamentos, condições e finalidades para aplicação, organização, desenvolvimento e avaliação dos cursos de graduação em engenharias (BRASIL, 2019).

Em 24 de abril de 2019, por meio da Resolução CNE/CES n2, o Conselho Nacional de Educação (CNE) instituiu Diretrizes Curriculares Nacionais (DCNs) dos Cursos de Graduação em Engenharia, que devem ser observadas pelas Instituições de Educação Superior (IES) no desenvolvimento e avaliação dos referidos cursos no âmbito de sistemas de educação superior no país (BRASIL, 2019). O prazo de implementação nos currículos das IESs é de três anos a partir da data da resolução.

Essa, substitui a Resolução CNE/CES nำ11, de 11 de março de 2002, e possui como foco principal o projeto político pedagógico do curso voltado ao desenvolvimento de competências e a capacitação docente para adoção de metodologias ativas. Além disso, Oliveira (2019) realiza um estudo comparativo das DCNs atuais e anteriores e destaca que as principais mudanças, além das citadas, foram a concepção e organização do curso, substituição de "sala de aula" por "ambiente de aprendizagem", organização nas novas DCNs, campos de atuação, acolhimento do ingressante e, considera como avanços a abordagem do perfil do egresso, avaliação dos estudantes e avaliação do curso.

Portanto, as DCNs atuais consideram como dever dos cursos de graduação em engenharia a especificação com clareza do perfil do egresso e das competências que devem ser desenvolvidas, tanto de caráter geral como específico:

"O curso de graduação em Engenharia deve possuir Projeto Político Pedagógico do Curso (PPC) que contemple o conjunto das atividades de aprendizagem e assegure 0 desenvolvimento das competências, estabelecidas no perfil do egresso (BRASIL, 2019).

Ainda o mesmo documento trata características, competências e habilidades, de forma a orientar os respectivos cursos. O Quadro 1 exibe competências e respectivas habilidades.

Quadro 1 - Competências e habilidades da Engenharia

\begin{tabular}{|c|c|}
\hline Competências Gerais & Habilidades \\
\hline \multirow{2}{*}{$\begin{array}{l}\text { I - Formular e conceber soluções } \\
\text { desejáveis de engenharia, analisando } \\
\text { e compreendendo os usuários dessas } \\
\text { soluções e seu contexto }\end{array}$} & $\begin{array}{l}\text { ser capaz de utilizar técnicas adequadas de observação, } \\
\text { compreensão, registro e análise das necessidades dos usuários e } \\
\text { de seus contextos sociais, culturais, legais, ambientais e } \\
\text { econômicos }\end{array}$ \\
\hline & $\begin{array}{l}\text { formular, de maneira ampla e sistêmica, questões de engenharia, } \\
\text { considerando o usuário e seu contexto, concebendo soluções } \\
\text { criativas, bem como o uso de técnicas adequadas }\end{array}$ \\
\hline \multirow{4}{*}{$\begin{array}{l}\text { Il - Analisar e compreender os } \\
\text { fenômenos físicos e químicos por meio } \\
\text { de modelos simbólicos, físicos e } \\
\text { outros, verificados e validados por } \\
\text { experimentação }\end{array}$} & $\begin{array}{l}\text { ser capaz de modelar os fenômenos, os sistemas físicos e químicos, } \\
\text { utilizando as ferramentas matemáticas, estatísticas, computacionais } \\
\text { e de simulação, entre outras }\end{array}$ \\
\hline & prever os resultados dos sistemas por meio dos modelos \\
\hline & $\begin{array}{l}\text { conceber experimentos que gerem resultados reais para } \\
\text { comportamento dos fenômenos e sistemas em estudo }\end{array}$ \\
\hline & verificar e validar os modelos por meio de técnicas adequadas \\
\hline III - Conceber, projetar e analisar & er e proj \\
\hline
\end{tabular}




\section{Competências Gerais}

sistemas, produtos (bens e serviços), componentes ou processos

- Implantar, supervisionar e controlar as soluções de Engenharia formas escrita, oral e gráfica

VI - Trabalhar e liderar equipes multidisciplinares

\section{Habilidades}

viáveis, técnica e economicamente, nos contextos em que serão aplicadas

projetar e determinar os parâmetros construtivos e operacionais para as soluções de Engenharia

aplicar conceitos de gestão para planejar, supervisionar, elaborar e coordenar projetos e serviços de Engenharia

ser capaz de aplicar os conceitos de gestão para planejar supervisionar, elaborar e coordenar a implantação das soluções de Engenharia

estar apto a gerir, tanto a força de trabalho quanto os recursos físicos, no que diz respeito aos materiais e à informação

desenvolver sensibilidade global nas organizações

projetar e desenvolver novas estruturas empreendedoras e soluções inovadoras para os problemas

realizar a avaliação crítico-reflexiva dos impactos das soluções de Engenharia nos contextos social, legal, econômico e ambiental

ser capaz de expressar-se adequadamente, seja na língua pátria ou em idioma diferente do Português, inclusive por meio do uso consistente das tecnologias digitais de informação e comunicação (TDICs), mantendo-se sempre atualizado em termos de métodos e tecnologias disponíveis

ser capaz de interagir com as diferentes culturas, mediante 0 trabalho em equipes presenciais ou a distância, de modo que facilite a construção coletiva

atuar, de forma colaborativa, ética e profissional em equipes multidisciplinares, tanto localmente quanto em rede

gerenciar projetos e liderar, de forma proativa e colaborativa, definindo as estratégias e construindo o consenso nos grupos

reconhecer e conviver com as diferenças socioculturais nos mais diversos níveis em todos os contextos em que atua (globais/locais)

preparar-se para liderar empreendimentos em todos os seus aspectos de produção, de finanças, de pessoal e de mercado

ser capaz de compreender a legislação, a ética e a responsabilidade profissional e avaliar os impactos das atividades de Engenharia na sociedade e no meio ambiente

VII - Conhecer e aplicar com ética a legislação e os atos normativos no âmbito do exercício da profissão

atuar sempre respeitando a legislação, e com ética em todas as atividades, zelando para que isto ocorra também no contexto em que estiver atuando

VIII - Aprender de forma autônoma e ser capaz de assumir atitude investigativa e autônoma, com vistas à lidar com situações e contextos aprendizagem contínua, à produção de novos conhecimentos e ao complexos, atualizando-se em relação desenvolvimento de novas tecnologias

aos avanços da ciência, da tecnologia e aos desafios da inovação

aprender a aprender

Fonte: Elaborado pelos autores com base em Brasil (2019)

As competências e habilidades, trazidas pelas DCNs, visam construir o perfil de engenheiro que possa atuar em campos da área e correlatos e se caracteriza pela aptidão 
do uso de tecnologias, visão holística e humanista, e reconheça as necessidades dos usuários considerando aspectos globais valendo-se de concepções multi e transdisciplinares na atividade profissional (BRASIL, 2019). São mencionadas oito competências e 24 habilidades necessárias para proporcionar melhor formação aos discentes dos cursos de graduação em Engenharia. As competências gerais descritas permeiam em função de conceber, formular, projetar, analisar, compreender, implantar, supervisionar, trabalhar, liderar e comunicar sobre aspectos relacionados às engenharias como um todo, como por exemplo, sistemas, soluções, fenômenos, entre outros. As ações previstas visam que o egresso (recém-formado em Engenharia) seja capaz de aplicar, na organização escolhida para trabalhar, os conhecimentos absorvidos e vivenciados no decorrer do curso de graduação. De forma que, as ações e saberes agreguem valores fundamentais tanto para a organização quanto para o próprio indivíduo (GONÇALVES, 2020).

No campo educacional, a competência é trabalhada para que o indivíduo seja capaz de executar adequadamente múltiplos conhecimentos, selecioná-los e integrá-los de forma ajustada à situação em questão (LIMA; ROCHA, 2012). Cada competência se traduz em habilidades que são a aptidão de um indivíduo em saber fazer algo, empregando seu conhecimento (GOMES, 2003). A habilidade é a capacidade de agir de forma concreta e de acordo com os objetivos ou processos das organizações, por isso, resultante da prática.

Segundo Chiavenato (2004) as habilidades estão fundamentadas em três aspectos: técnico, humano e conceitual. O aspecto técnico está relacionado ao conhecimento especializado de métodos e técnicas fundamentais para a realização das tarefas. $\mathrm{O}$ aspecto humano se relaciona com a possibilidade de sustentação do convívio em equipe, com o entendimento dos sentimentos e diferenças existentes entre o ser humano. Já o aspecto conceitual está voltado para a capacidade de lidar com ideias e conceitos abstratos de forma cognitiva. Os três aspectos, juntos, se complementam e trazem a melhor formação.

\section{SOFT E HARD SKILLS}

As mudanças no mundo impactam a forma de como ensinar para preparar profissionais que atendam às necessidades e a volatilidade das mudanças, no qual o modelo de gestão centrado no cargo passa a ser ponderado (FLEURY; FLEURY, 2001) porque são demandados do mercado, profissionais que unam as hard skills e soft skills (KERN, et. al., 2019). Na Engenharia, as DCNs enfatizam a necessidade de atributos socioemocionais aliados aos conhecimentos técnicos. Aqui, discute-se, brevemente, esses dois conhecimentos necessários à formação profissional.

De forma análoga à dificuldade de conceituação do tema de competências, a classificação destas é um tema frágil porque as organizações podem se concentrar nas que são tidas como mais importantes, em detrimento das outras (WOODRUFFE, 1993). Mas de outro lado, a necessidade da implementação das DCNs exige a reestruturação dos currículos para o desenvolvimento das competências. O que fomenta estudos na temática como subsídio à construção dos instrumentos avaliativos das competências esperadas nos alunos/egressos de Engenharia, bem como estabelecer metodologias e ações de ensino que as desenvolvam de forma conjunta e/ou associada.

Nessa acepção, os termos de língua inglesa elencados na literatura que em seu constructo convergem como soft skills são "generic skills, transversal skills, people skills, key qualifications, critical abilities, transferable skills, employability capacities" (SWIATKIEWICZ, 2014). Assim, Mitchell, Skinner e White (2010) consideram que o termo soft skills é um conjunto de habilidades que podem ser utilizadas no trabalho, visto como 
atributos de carreira, tais como habilidades de comunicação, pessoais, de liderança e solução de problemas. Em conformidade, Deepa e Seth (2013) acrescentam habilidades de comunicação, interpessoais, individuais e inteligência emocional.

$\mathrm{Na}$ literatura de língua portuguesa, as softs skills são trabalhadas como competências transversais, competências comportamentais, habilidades transferíveis, e habilidades socioemocionais (SOUZA; CAMPOS, 2018; FAGNANI et al., 2020). Assim, Swiatkiewicz (2014) descreve-as com habilidades universais/transversais não acadêmicas e sem associação com funções técnicas, mas vista como traços de personalidades, atributos de carreira, objetivos, preferências e motivações.

Em Mitchell, Skinner e White (2010), as principais soft skills demandadas e valorizadas pelo mercado de trabalho foram: comunicação, ética, gestão do tempo, comunicação escrita, trabalho em equipe, ética empresarial, flexibilidade, serviço ao cliente, solução de problemas/pensamento crítico, comunicação oral e liderança.

De outro segmento, Padmaja (2012) discorre que as hard skills são adquiridas nas escolas e universidades e são habilidades necessárias para o exercício profissional obtidas e materializadas por diplomas e certificados. Deepa e Seth (2013) complementam ao elucidar que abrangem um conjunto de conhecimentos de domínio técnico. Swiatkiewicz (2014) trabalha as hard skills como competências técnicas e discorre que são adquiridas pela formação profissional, acadêmica ou pela experiência no exercício das atividades organizacionais. Em seu estudo, as mais valorizadas pelas organizações foram: conhecimento/habilidades técnicas, habilitações, cumprimentos de padrões de segurança, conhecimento de línguas, experiência profissional e conhecimentos de informática.

Padamaja (2012) explica que as hard skills são pré-requisitos para conseguir uma posição no mercado, embora não sejam suficientes para a melhor posição. Suscitando, como discutido por Mello e Araújo (2019) que talvez as habilidades técnicas não sejam mais as características fundamentais na seleção e contratação de profissionais de engenharia. Então, infere-se que as soft skills representam um diferencial de sucesso profissional (HECKAMN; KAUTZ, 2012)

\section{MÉTODO DE PESQUISA}

$\mathrm{Na}$ ciência, os conceitos que constituem os modelos, que representam a ordem, são obtidos no conhecimento existente nas referências bibliográficas. Mas, não basta ter contato com o conhecimento existente sobre a ordem, lendo em inúmeras referências sobre o assunto. Faz-se necessário articular os conceitos pertinentes de modo a fazer sentido para estabelecer a ordem no modelo (MARTINS, 2012). Tais articulações são possíveis quando há análise e interpretação do material bibliográfico (MARCONI; LAKATOS, 2003).

Este trabalho, de natureza básica e abordagem qualitativa, trata-se de uma pesquisa teórica que traz discussões, a partir da literatura, revisões bibliográficas e modelagens conceituais (NAKANO, 2012). Para isso, é realizada uma pesquisa bibliográfica. A pesquisa bibliográfica, também chamada de levantamento bibliográfico, é uma revisão da literatura sobre as principais teorias que norteiam o trabalho científico, a qual pode ser realizada em diversas fontes como livros, periódicos, instrumentos legais, entre outros (PIZZANI, 2012).

Sob ponto de vista da abordagem, a pesquisa qualitativa é um guarda-chuva que abriga uma série de técnicas de interpretação que procuram descrever, decodificar, traduzir e qualquer outro termo relacionado com o entendimento e não com a frequência de ocorrência das variáveis de determinado fenômeno (MARTINS, 2012). Essa abordagem traz consigo uma sequência de atividades que envolve a análise de dados, organização, 
sua categorização, interpretação e, por fim, a redação do relatório (PRODANOV; FREITAS, 2013).

O tema e objetivo tratado neste artigo (proposta de classificação das competências gerais trazidas nas DCNs dos cursos de Engenharia, em hard e soft skills), são favorecidos pela pesquisa e revisão bibliográfica (conteúdo relacionado ao tema competências, hard e soft skills), juntamente com interpretação das informações trazidas no documento oficial das DCNS dos cursos de graduação em Engenharia, seguida pela análise cruzadas dessas informações e posterior classificação. Insere-se, portanto, em uma pesquisa com objetivo exploratório, relativamente estruturada.

Como procedimentos para o desenvolvimento deste trabalho, tem-se, prioritariamente, o instrumento de pesquisa documental, que utiliza de arquivo público, para a análise e interpretação junto com documentos da literatura. $O$ principal arquivo público utilizado é a Resolução CNE/CES №2 de 24 de abril de 2019. Os procedimentos podem ser organizados em três etapas. A primeira etapa trata-se da pesquisa documental, na qual foi analisado o instrumento de orientação das DCNs, com leituras críticas e busca por maior entendimento relativo aos aspectos de competências e habilidades a serem desenvolvidas nos egressos dos cursos de graduação de engenharias. Na segunda etapa, de revisão de literatura foram buscadas, na literatura, artigos recentes que tratassem sobre os temas competências, hard e soft skills, além de materiais que já abordassem interpretações sobre o instrumento de orientação das DCNs. Já a terceira etapa, de análise cruzada das informações, fundamental para este trabalho, fez o confronto entre as informações da literatura e do instrumento de orientação das DCNs, ou seja, a classificação final das habilidades trazidas nas DCNs entre hard e soft skills.

\section{$5 \quad$ HABILIDADES X SOFT E HARD SKILLS}

Tendo em vista a teoria abordada sobre as DCNs, competências, habilidades, soft skills e hard skills, é proposta a classificação, em hard e soft skills, das habilidades trazidas nas DCNs em Engenharia.

O Quadro 2 elenca as habilidades das DCNs classificadas como hard skills. Tratase da seleção das habilidades que constam no Quadro 1 as quais, conforme Deepa e Seth (2013) e Padamaj (2012), abrangem um conjunto de conhecimentos/habilidades técnicas, adquiridos em decorrência da formação e necessárias para o exercício profissional. Dessa forma a previsão, verificação e validação de modelos, modelagem de fenômenos, aplicação de conceitos de gestão, determinação de parâmetros são conhecimentos adquiridos na formação universitária em engenharia e, essenciais à atuação profissional.

\section{Quadro 2 - Classificação das DCNs em hard skills}

\section{Hard skills}

Ser capaz de utilizar técnicas adequadas de observação, compreensão, registro e análise das necessidades dos usuários e de seus contextos sociais, culturais, legais, ambientais e econômicos

Ser capaz de modelar os fenômenos, os sistemas físicos e químicos, utilizando as ferramentas matemáticas, estatísticas, computacionais e de simulação, entre outras

Prever os resultados dos sistemas por meio dos modelos

Conceber experimentos que gerem resultados reais para o comportamento dos fenômenos e sistemas em estudo

Verificar e validar os modelos por meio de técnicas adequadas

Projetar e determinar os parâmetros construtivos e operacionais para as soluções de Engenharia

Aplicar conceitos de gestão para planejar, supervisionar, elaborar e coordenar projetos e serviços de Engenharia 
Ser capaz de aplicar os conceitos de gestão para planejar, supervisionar, elaborar e coordenar a implantação das soluções de Engenharia

Estar apto a gerir, tanto a força de trabalho quanto os recursos físicos, no que diz respeito aos materiais e à informação

Fonte: Elaborado pelos autores com base em Brasil (2019)

Já para as soft skills, o Quadro 3 lista as habilidades juntamente com autores que trazem trabalhos definições, explanações e exemplos de soft skills similares às divulgadas nas DCNs, corroborando com a referida classificação. Então, do mesmo modo que Mitchell, Skinner e White (2010) e Swiatkiewicz (2014), Robles (2012) cita como soft skills mais frequentes, dentre as respostas dos executivos entrevistados em sua pesquisa, as habilidades de comunicação, flexibilidade, cortesia, habilidades interpessoais, atitude positiva, integridade, responsabilidade, profissionalismo, ética e trabalho em equipe.

É notório na análise que, autores de áreas de conhecimento distintas, convergem, na maioria das vezes, para com as opiniões acerca das soft skills demandas pelo mercado e, trazidas nas DCNs. Tem-se assim, 15 competências das DCNs associadas às soft skills.

\section{Quadro 3 - Classificação das DCNS em soft skills e autores associados}

\begin{tabular}{|c|c|}
\hline Soft skills & Autores \\
\hline $\begin{array}{l}\text { Preparar-se para liderar empreendimentos em todos os seus aspectos } \\
\text { de produção, de finanças, de pessoal e de mercado }\end{array}$ & $\begin{array}{l}\text { Mitchell, Skinner e White (2010); } \\
\text { Robles (2012), }\end{array}$ \\
\hline $\begin{array}{l}\text { Atuar sempre respeitando a legislação, e com ética em todas as } \\
\text { atividades, zelando para que isto ocorra também no contexto em que } \\
\text { estiver atuando }\end{array}$ & $\begin{array}{l}\text { Mitchell, Skinner e White (2010); } \\
\text { Robles (2012), }\end{array}$ \\
\hline $\begin{array}{l}\text { Formular, de maneira ampla e sistêmica, questões de engenharia, } \\
\text { considerando o usuário e seu contexto, concebendo soluções criativas, } \\
\text { bem como o uso de técnicas adequadas }\end{array}$ & $\begin{array}{l}\text { Mitchell, Skinner e White (2010); } \\
\text { Robles (2012) }\end{array}$ \\
\hline $\begin{array}{l}\text { Ser capaz de conceber e projetar soluções criativas, desejáveis e } \\
\text { viáveis, técnica e economicamente, nos contextos em que serão } \\
\text { aplicadas }\end{array}$ & $\begin{array}{l}\text { Mitchell, Skinner e White (2010); } \\
\text { Robles (2012); Swiatkiewicz } \\
\text { (2014) }\end{array}$ \\
\hline $\begin{array}{l}\text { Projetar e desenvolver novas estruturas empreendedoras e soluções } \\
\text { inovadoras para os problemas }\end{array}$ & $\begin{array}{l}\text { Mitchell, Skinner e White (2010); } \\
\text { Swiatkiewicz (2014) }\end{array}$ \\
\hline $\begin{array}{l}\text { Ser capaz de compreender a legislação, a ética e a responsabilidade } \\
\text { profissional e avaliar os impactos das atividades de Engenharia na } \\
\text { sociedade e no meio ambiente }\end{array}$ & Robles (2012) \\
\hline Desenvolver sensibilidade global nas organizações & $\begin{array}{l}\text { Robles (2012); Swiatkiewicz } \\
\text { (2014) }\end{array}$ \\
\hline $\begin{array}{l}\text { Realizar a avaliação crítico-reflexiva dos impactos das soluções de } \\
\text { Engenharia nos contextos social, legal, econômico e ambiental }\end{array}$ & $\begin{array}{l}\text { Mitchell, Skinner e White (2010); } \\
\text { Robles (2012) }\end{array}$ \\
\hline $\begin{array}{l}\text { Ser capaz de expressar-se adequadamente, seja na língua pátria ou em } \\
\text { idioma diferente do Português, inclusive por meio do uso consistente das } \\
\text { tecnologias digitais de informação e comunicação (TDICs), mantendo- } \\
\text { se sempre atualizado em termos de métodos e tecnologias disponíveis }\end{array}$ & $\begin{array}{l}\text { Swiatkiewicz (2014); Robles } \\
\text { (2012) }\end{array}$ \\
\hline $\begin{array}{l}\text { Ser capaz de interagir com as diferentes culturas, mediante o trabalho } \\
\text { em equipes presenciais ou a distância, de modo que facilite a construção } \\
\text { coletiva }\end{array}$ & $\begin{array}{l}\text { Mitchell, Skinner e White (2010); } \\
\text { Swiatkiewicz (2014) }\end{array}$ \\
\hline $\begin{array}{l}\text { Atuar, de forma colaborativa, ética e profissional em equipes } \\
\text { multidisciplinares, tanto localmente quanto em rede }\end{array}$ & $\begin{array}{l}\text { Mitchell, Skinner e White (2010); } \\
\text { Robles (2012) }\end{array}$ \\
\hline $\begin{array}{l}\text { Gerenciar projetos e liderar, de forma proativa e colaborativa, definindo } \\
\text { as estratégias e construindo o consenso nos grupos }\end{array}$ & $\begin{array}{l}\text { Mitchell, Skinner e White (2010); } \\
\text { Robles (2012); Swiatkiewicz } \\
\text { (2014) }\end{array}$ \\
\hline $\begin{array}{l}\text { Reconhecer e conviver com as diferenças socioculturais nos mais } \\
\text { diversos níveis em todos os contextos em que atua (globais/locais) }\end{array}$ & $\begin{array}{l}\text { Mitchell, Skinner e White (2010); } \\
\text { Robles (2012); Swiatkiewicz } \\
\text { (2014) }\end{array}$ \\
\hline
\end{tabular}




\begin{tabular}{|l|l|}
\hline \multicolumn{1}{|c|}{ Soft skills } & \multicolumn{1}{c|}{ Autores } \\
\hline $\begin{array}{l}\text { Ser capaz de assumir atitude investigativa e autônoma, com vistas à } \\
\text { aprendizagem contínua, à produção de novos conhecimentos e ao } \\
\text { desenvolvimento de novas tecnologias }\end{array}$ & $\begin{array}{l}\text { Robles (2012); Swiatkiewicz } \\
\text { (2014) }\end{array}$ \\
\hline Aprender a aprender & $\begin{array}{l}\text { Robles (2012); Swiatkiewicz } \\
\text { (2014) }\end{array}$ \\
\hline
\end{tabular}

Fonte: Elaborado pelos autores com base na literatura

Em última análise, com a categorização percebe-se que a associação das soft e hard skills na literatura consultada e expostas nas DCNs em Engenharia se unem a fim de construir o perfil do engenheiro demandado pelo mercado. Assim, as habilidades não se encerram em um conjunto de conhecimentos, mas desembocam em competências elencadas no Quadro 1, vistas como produtos esperados do processo formativo em Engenharia.

\section{CONCLUSÕES}

Para a classificação das DCNs da Engenharia em soft skills e hard skills, proposta deste trabalho, foi necessária uma análise da literatura e de trabalhos existentes, de forma a embasar e alinhar o resultado. Os trabalhos existentes trouxeram uma gama de habilidades, sobretudo soft skills, que tinham grande semelhança com algumas habilidades elencadas pelas DCNs, corroborando a classificação.

As DCNs trazem 24 habilidades, das quais 15 foram classificadas em soft skills e nove habilidades tiveram proximidade com hard skills. As hard skills, habilidades técnicas, em menor número, aparentemente, sempre se fizeram presentes nos currículos das engenharias, e são consideradas de forma bruta na formação dos futuros engenheiros. Já as soft skills, habilidades comportamentais e socioemocionais, em maior número, são destaques, especialmente, pelas diferenças e exigências do mercado de trabalho.

É perceptível, atualmente, uma crescente no número de cursos de engenharia no Brasil, que trazem currículos e formação técnica muito semelhantes entre si. Este fato, eleva a oferta de tais profissionais no mercado e, ainda, com características técnicas comuns. Como, então, esses profissionais podem se diferenciar? As soft skills são um meio possível para isso e, reconhecidas, não apenas pelo mercado de trabalho (empregadores) mas também pelos conselhos superiores de educação e ensino. Esse reconhecimento está presente no maior número de soft skills nas DCNs das engenharias.

Assim como a maior parte das pesquisas, também, nesta, estão presentes limitações. As principais, residem na fragilidade da temática frente a volatilidade do mercado de trabalho que passam a redefinir suas necessidades constantemente. Além disso, o cunho de inovação da classificação pode conferir estranheza aos atores envolvidos. Assim, sugere-se como trabalhos futuros: quais as soft skills e hard skills demandadas pelo mercado brasileiro de Engenharia, ou ainda, como as soft e hard skills são trabalhadas no curso de engenharia, nas instituições estrangeiras que possuem currículo por competências. Ainda, espera-se que esta proposição culmine em instrumentos e elementos curriculares que viabilizem, nos seus respectivos eixos formativos, 0 desenvolvimento das competências gerais no perfil do egresso de Engenharia.

\section{Agradecimentos}

Ao apoio financeiro da Universidade Federal Rural do Semi-Árido (UFERSA) em decorrência do projeto "As Capacidades Dinâmicas e Operacionais no ambiente universitário" devidamente cadastrado na Pró-Reitoria de Pesquisa e Pós-Graduação. 


\section{REFERÊNCIAS}

ANGELO, Debora M. P. de; GIANESI, Irineu G. N. O projeto pedagógico para as novas diretrizes curriculares para a Engenharia. In: OLIVEIRA, Vanderli F. de (Org.). A

Engenharia e as novas DCNs: oportunidades para formar mais e melhores engenheiros. Rio de Janeiro: LTC, 2019.

BAZZO, Walter A.; COSTA, Luciano A. C. da. A Revolução 4.0 e seus impactos na formação do professor em engenharia. Revista de Ensino em Engenharia, online, v. 38, n. 3, p. 28-39, 2019

BRASIL. Conselho Nacional de Educação. Parecer CNE/CES n776, de 03 de dezembro de 1997. Orientações para as diretrizes curriculares dos cursos de graduação. Diário Oficial da República Federativa do Brasil. Brasília. 1997.

BRASIL. Conselho Nacional de Educação. Resolução CNE/CES n², de 24 de abril de 2019. Diretrizes Curriculares Nacionais do Curso de Graduação em Engenharia. Diário Oficial da República Federativa do Brasil. Brasília. 2019.

CHIAVENATO, Idalberto. Introdução à teoria geral da administração. 3. ed. Rio de janeiro: Elsevier, 2004.

DEEPA, Sethi; SETH Manisha. Do Soft Skills Matter? - Implications for Educators Based on Recruiters' Perspective. IUP Journal of Soft Skills, v. 7, n. 1, p. 7, 2013.

ELMÔR FILHO, Gabriel et al. Uma nova sala de aula é possível: aprendizagem ativa na educação em engenharia. 1. ed, Rio de Janeiro: LTC, 2019.

FAGNANI Laura et al. Soft skills na engenharia: um relato de caso do ICT/UNIFESP. In: XLVIII Congresso Brasileiro de Educação em Engenharia, 2020, Anais. online.

FLEURY, Maria T.; FLEURY, Afonso. Construindo o conceito de competência. Revista de administração contemporânea, v. 5, n. SPE, p. 183-196, 2001.

GOMES, D. Competências e Habilidades do Diretor. Campo Grande: UCDB, 2003.

GONÇALVES, Rodrigo F. Habilidades e competências requeridas ao profissional de tecnologia da informação. 2020. Monografia - Curso de Engenharia de Software. Instituto de Ciências Exatas e Tecnologia da Universidade Federal do Amazonas, Itacoatiara, 2020. Disponível em: http://riu.ufam.edu.br/.

HECKMAN, James J.; KAUTZ, Tim. Hard evidence on soft skills. Labour economics, v. 19, n. 4, p. 451-464, 2012.

KERN, Mauro et. al.A mobilização empresarial pela inovação (MEI) e a defesa da modernização do ensino de Engenharia. In: OLIVEIRA, Vanderli F. de (Org.). A 
Engenharia e as novas DCNs: oportunidades para formar mais e melhores engenheiros. Rio de Janeiro: LTC, 2019.

LIMA, Marcos A. M; ROCHA, Bianca P. L. Avaliação de programas de gestão por competências: um estudo em organizações da Região Metropolitana de Fortaleza-CE. Organizações em contexto, v. 8, n. 16, 2012.

MARCONI, Marina de A.; Lakatos, Eva M. Fundamentos de metodologia científica. 5. ed. São Paulo: Atlas, 2003.

MELLO, Luciana T. C. de, ARAÚJO, Richardson B. C. As capacidades dinâmicas e operacionais no ambiente universitário In: XLVII Congresso Brasileiro de Educação em Engenharia, 2019, Anais. Fortaleza.

MARTINS, Roberto A. Abordagens quantitativa e qualitativa. In: MARTINS, Roberto. Antonio (Org.). Metodologia de pesquisa em engenharia de produção e gestão de operações. 2. ed. Rio de Janeiro: 2012.

MITCHELL, Geana W.; SKINNER, Leane B.; WHITE, Bonnie J. Essential Soft Skills for success in the twenty-first century workforce as perceived by business educators. Delta Pi Epsilon Journal. vol. 52, n. 1, p. 43-53, 2010.

NAKANO, D. N.: Métodos de pesquisa adotados na Engenharia de Produção e gestão de operações. In: MIGUEL, P.A.C. (Coord.). Metodologia de pesquisa em Engenharia de Produção e Gestão de Operações. 2. ed. São Paulo: Elsevier, 2012.

OLIVEIRA, Vanderli F. de. As inovações nas atuais diretrizes para a Engenharia: estudo comparativo com as anteriores. In: OLIVEIRA, Vanderli F. de (Org.). A Engenharia e as novas DCNs: oportunidades para formar mais e melhores engenheiros. Rio de Janeiro: LTC, 2019.

PADMAJA, T. V. S. Role of soft skills in enhancing employability. India J. Edu. Inf. Manage, v. 1, n. 4, 2012.

PIZZANI, Luciana et al. A arte da pesquisa bibliográfica na busca do conhecimento. Revista Digital de Biblioteconomia e Ciência da Informação, Campinas, v. 10, n. 1, p. 53-66, 2012.

PRADO, Fabio do; DONATO; Gustavo H. B. Visão, protagonismo e domínio do processo inovador como forças motrizes do processo de aprendizado. In: OLIVEIRA, Vanderli F. de (Org.). A Engenharia e as novas DCNs: oportunidades para formar mais e melhores engenheiros. Rio de Janeiro: LTC, 2019.

PRODANOV, Cleber Cristiano; FREITAS Ernani C. Metodologia do trabalho científico: métodos e técnicas da pesquisa e do trabalho acadêmico 2. ed. Novo Hamburgo: Feevale, 2013. 
ROBLES, Marcel M. Executive perceptions of the top 10 soft skills needed in today's workplace. Business Communication Quarterly, v. 75, n. 4, p. 453-465, 2012.

SOUZA, Alana S.; CAMPOS, Lílian B. P. Habilidades transversais de engenheiros em formação: o papel de projetos de extensão. In: XLVI Congresso Brasileiro de Educação em Engenharia, 2018, Anais. Salvador.

SWIATKIEWICZ, Olgierd. Competências transversais, técnicas ou morais: um estudo exploratório sobre as competências dos trabalhadores que as organizações em Portugal mais valorizam. Cad. EBAPE.BR, vol.12, n.3, p. 633-687, 2014.

WOODRUFFE, Charles. What is meant by a competency? Leadership \& Organization Development Journal, v. 14, n. 1, p. 29-36, 1993.

\title{
A PROPOSAL FOR CLASSIFICATION OF THE SKILLS OF NATIONAL CURRICULUM GUIDELINES IN SOFT SKILLS AND HARD SKILLS
}

\begin{abstract}
The formative process of engineering education needed to be restructured so that professionals act according to the needs of the labor market and society. Thus, Resolution CNE/CES no2, of April 24, 2019, establishes National Curricular Guidelines (NCGs) for the Undergraduate Engineering Course, which promote changes, when compared with the previous ones. Among these, the design of the curriculum by competences is one of the most innovative points. Thus, this paper proposes a classification of the skills listed in the NCGs into hard and soft skills. Because of the need imposed in the university environment, in which the transmission of technical knowledge is supplanted by the development of competences, skills and attitudes that form citizen-engineers, the classification according to the literature records that elucidates the individual's need for soft skills is relevant. And hard skills to achieve a prominent place in the market. For this, documentary research is used, followed by bibliographic research. The results obtained, using the technique of cross analysis of the information, results that of the 24 general competences expected of the graduate in Engineering: nine are categorized as hard skills and the other 15 competences are classified as soft skills, through the consulted literature. Thus, they are hard skills applying concepts of management, verification and validation of models through appropriate techniques. And skills such as developing global sensitivity in organizations and conducting a critical-reflexive assessment of the impacts of engineering solutions in the social, legal, economic and environmental contexts are classified as soft skills.
\end{abstract}

Keywords: Competences. Abilities. Graduate profile. Hard skills. Soft skills. 